\title{
Bioactive Glass-Green and Red Propolis Association: Antimicrobial Activity Against Oral Pathogen Bacteria \\ Walison A Vasconcelos ${ }^{1}$, Neilor M A Braga ${ }^{2}$, Vitor R Chitarra ${ }^{3}$, Vagner R Santos ${ }^{3 *}$, Ângela L Andrade ${ }^{4}$ and Rosana Z Domingues ${ }^{5}$
}

${ }^{1}$ Department of Restorative Dentistry, Dentistry School, Federal University of Minas Gerais, Belo Horizonte, MG, Brazil

${ }^{2}$ Department of Restorative Dentistry, Dentistry School, Estadual University of Montes Claros, Montes Claros, MG, Brazil

${ }^{3}$ Laboratory of Microbiology and Biomaterials, Dentistry School, Federal University of Minas Gerais, Belo Horizonte, MG, Brazil

${ }^{4}$ Department de Química-ICE, Federal University of Ouro Preto, Ouro Preto, MG, Brazil

${ }^{5}$ Department de Química-ICEX, Federal University of Minas Gerais, Belo Horizonte, MG, Brazil

\begin{abstract}
Bioactive glasses were studied as potential drug delivery candidates for the incorporation and release of natural products. In light of these studies, the antimicrobial activity of a new formulation containing propolis was evaluated. Susceptibility of oral pathogens microorganisms were evaluated using the CLSI standard MIC, MBC and agar diffusion method with Brazilian green (BGP) and red (BRP) propolis extracts isolated and associated with bioglass (BGGP and BGRP). Isolated Bioglass (BG), Tetracycline (TT) and Ethanol (ET) were the controls. Results data were expressed as $M \pm S D$. Significant differences between microorganisms treated groups antimicrobial assays were analyzed by Student's-test (significance at) using the Origin 6.0 program. All tested bacteria were susceptible to bioglassincorporated green and red propolis. The new formulation was effective for inhibiting the in vitro microorganisms growth after 24 and 48 hours at $37^{\circ} \mathrm{C}$ in an atmosphere specific to each microorganism. Red propolis being more active than the green one. Propolis incorporated into bioglass did not lose its antimicrobial properties. The positive results suggest that propolis in this sustained release formulation should be further tested as an alternative therapy against infectious agents of the oral cavity.
\end{abstract}

Keywords: Green propolis; Red propolis; Bioactive glass; Antimicrobial activity; Oral microorganisms; MIC, in vitro test

\section{Introduction}

Dental caries, root canal infections, dental periapical abscesses and osteomyelitis in the maxilla and mandible are infections caused by oral microorganisms associated or not to Streptococcus mutans, Staphylococcus aureus and Enteroroccus faecalis. Streptococcus mutans, Streptococcus salivarius, Streptococcus sanguinis and Lactobacillus casei are been implicated as a causative agent of dental caries in humans and are a number of virulence factors that enable it to colonize tooth surfaces [1]. Staphylococcus aureus, followed by Streptococcus are the most common organisms causing infection and the antibacterial treatment should be targeted against these organisms in mild infection, possibly with monotherapy [2]. Staphylococcus aureus has relevance in acute and chronic abscesses occurence in the oral cavity, and may be associated with chronic osteomyelitis of the mandible and maxilla $[3,4]$. Porphyromonas gingivalis, Prevotella intermedia, Aggregatibacter actinomycetemcomitans, Fusobacterium nucleatum, and Enterococcus faecalis are oral common inhabitants of the human periodontal and endodontic tracts and are also able to colonize a variety of other sites [5-7]. These microorganisms have been associated with gingivitis and periodontitis and oral mucosal lesions in immunocompromised patients, and root canal infections $[8,9]$.

Over the last few decades, worldwide increase in the use of natural products for pharmacological purposes has been observed [10,11]. Currently, there are a growing number of studies in different medical specialties using natural substances, such as teas or extracts from various plants. Among the natural extracts used in dentistry, propolis stands out due to its anti-inflammatory, analgesic and antimicrobial properties [12-14]. Propolis is a resinous substance collected by honeybees from tree buds and sap [15]. Bees bring the resin to the hive and mix it with their own secretions, such as bee wax and saliva [13]. Propolis is thought to be used to seal unnecessary holes and cracks in the hive and to protect the bee colony against intruders, viruses, fungi, and bacteria $[16,17]$. Propolis is used in folk medicine in many regions worldwide and has been reported to have various biological and physiological activities, such as antibacterial $[18,19]$, antiviral [20], anti- inflammatory [21,22], and anticancer [23-25] effects. Propolis contains numerous chemical ingredients, including cinnamic acid derivatives (e.g., p-coumaric acid, drupanin, artepillin C, baccharin, benzoic acids, substituted phenolic acids, flavonoids, and amino acids [26,27], and the chemical composition of propolis depends on various factors, such as the geographical origin, types of plant sources [28], and season of the year [26]. Baccharis dracunculifolia DC (Asteraceae) [29,30], a plant native to Brazil, is the most important botanical source of southeastern Brazilian propolis, which is known as green propolis because of its deep green color [21,31]. Propolis is readily available from commercial sources and is used as a popular treatment for infectious conditions of the oral cavity and throat $[32,33]$.

Bioactive glasses have been used extensively in medicine for middle ear surgery and have been applied to dentistry in the treatment of bone defects, periodontal disease and pulpotomy [34,35]. Bioactive glasses have the ability to develop a chemical bond with bone surface and bony tissue by inducing the formation of a hydroxyapatite layer on the surface when in contact with biological fluids [36-39]. Previous study demonstrated bioactive glasses- propolis incorporation as potential drug delivery candidates to be used in oral lesions [40]. So, this study aimed to verify the effectiveness of propolis incorporated by bioactive glasses activity against oral pathogens bacteria.

${ }^{*}$ Corresponding author: Vagner Rodrigues Santos, Department Oral Clinical Oral Pathology, Oral Surgery, Faculdade de Odontologia, Universidade Federal de Minas Gerais, Avenida Antonio Carlos 6627 - Campus Pampulha, Belo Horizonte Minas Gerais, Brazil, CEP 31270-901, Tel: +55-31-3409-2497; Fax: +55-31-34092430;; E-mail: vegneer2003@yahoo.com.br

Received September 10, 2014; Accepted October 15, 2014; Published October 17, 2014

Citation: Vasconcelos WA, Braga NMA, Chitarra VR, Santos VR, Andrade ÂL (2014) Bioactive Glass-Green and Red Propolis Association: Antimicrobial Activity Against Oral Pathogen Bacteria. Nat Prod Chem Res 2: 154. doi:10.4172/2329-6836.1000154

Copyright: (c) 2014 Vasconcelos WA, et al. This is an open-access article distributed under the terms of the Creative Commons Attribution License, which permits unrestricted use, distribution, and reproduction in any medium, provided the original author and source are credited. 


\section{Materials and Methods}

\section{Propolis samples and Preparation of Ethanol Propolis Extract}

Brazilian propolis samples: Propolis sample were collected in the Brazilian state of Minas Gerais. Green propolis (BGP) were produced by Apis mellifera and collected from the Pharmanectar apiary in Nova Lima (Minas Gerais State, Brazil). Bacharis dracunculifolia, popular named alecrim, is the tree of green propolis origin [41]. Chemical markers of green propolis used in this study are shown in Table 1 . The other propolis sample were collected in the state of Alagoas Brazilian State was typified is red propolis (BRP). The red propolis origin from Dalbergia ecastophyllum tree [41,42]. Tables 1 and 2 show the main markers chemical constituents of Brazilian green and red propolis [43].

The ethanolic extracts of propolis were prepared by using a modified technique $[44,45]$. Propolis $(30 \mathrm{~g})$ was cut into small pieces and extracted with $100 \mathrm{ml}$ absolute ethanol at room temperature for $24 \mathrm{~h}$. The solution was filtered with Whattman paper number 3, and placed in amber flasks. Each solution was dried and the residue weighted to prepare stock solution in ethanol at concentration of $5 \%$. The final concentration of the solvent in the experiments did not exceed $0.1 \%$ ethanol.

\section{Bioactive glass preparation}

Bioactive glass was prepared using a sol-gel process [40]. A sol with composition $\left(\mathrm{SiO}_{2}\right)_{0.80}\left(\mathrm{P}_{2} \mathrm{O}_{5}\right)_{0.04}(\mathrm{CaO})_{0.16}$ was prepared utilizing tetraethoxysilane (TEOS), triethylphosphate, and calcium chloride as $\mathrm{Si}, \mathrm{P}$, and $\mathrm{Ca}$ precursors, respectively. Afterwards, $0.04 \mathrm{~g}$ of propolis was loaded into sol-gel solutions. Green Propolis (GP) and Red Propolis (RP) samples were added to the sol-gel solution. The

\begin{tabular}{|l|l|c|}
\hline$N^{\circ}$ & Compounds & $\mathrm{mg} / \mathrm{g}$ \\
\hline 1 & Coumaric acid & 3.56 \\
\hline 2 & Cinnamic acid & 1.66 \\
\hline 3 & Quercetin & 1.38 \\
\hline 4 & Kaempferol & 1.77 \\
\hline 5 & Isorhamnetin & 0,91 \\
\hline 6 & Sakuranetin & 5.57 \\
\hline 7 & Pinobanskin-3-acetate & 13.92 \\
\hline 8 & Chrysin & 3.51 \\
\hline 9 & Galangin & 9.75 \\
\hline 10 & Kaempferide & 11.60 \\
\hline 11 & Artepillin C & 82.96 \\
\hline
\end{tabular}

Table 1: Chemical constituents markers of Brazilian green propolis sample BGP from Baccharis dracunculifoila (SBN97). HPLC test [12].

\begin{tabular}{|c|c|c|}
\hline Number & Compounds & Contents $\mathbf{( m g} / \mathbf{g})$ \\
\hline 01 & Rutin & 0.7 \\
\hline 02 & Liquiritigenin & 1.8 \\
\hline 03 & Daidzein & 0.3 \\
\hline 04 & Pinobanksin & 1.7 \\
\hline 05 & Quercetin & 0.5 \\
\hline 06 & Luteolin & 1.2 \\
\hline 07 & Dalbergin & 0.4 \\
\hline 08 & Isoliquiritigenin & 4.8 \\
\hline 09 & Formononetin & 10.2 \\
\hline 10 & Pinocembrin & 3.3 \\
\hline 11 & Pinobanksin-3-acetate & 1.7 \\
\hline 12 & Biochanin A & 0.5 \\
\hline
\end{tabular}

Table 2: Flavonoids and other chemical constituents of Brazilian redpropolis from Dalbergia ecastophyllum[37]. percentage (w/t.\%) of propolis was approximately $2 \%$. Reagent grade chemicals (Fluka) were used as received. All the samples were placed in a humidified atmosphere overnight in an amber bottle. Specimens solid isolated bioglass (BG) and bioglass green propolis (BGGP) and Bioglass red propolis (BGRP) associated with $6.0 \mathrm{~mm}$ in diameter and $1.0 \mathrm{~mm}$ height were used as test.

\section{The antimicrobial susceptibility test}

Antimicrobial susceptibility test was performed by Minimum Inhibitory Concentration (MIC) and Minimum Bactericidal Concentration (MBC), and by means of agar diffusion discs, in compliance with the rules of the Clinical and Laboratory Standards Institute [46]. The freeze-dried microorganisms were cultivated in brain heart infusion - BHI (Difco-USA). Aliquots of $500 \mu \mathrm{L}$ of the overnight cultures of each microorganism Streptococcus mutans (ATCC 70069), Staphylococcus aureus (ATCC 27664), Porphyromonas gingivalis (ATCC 33277), Prevotella intermedia (ATCC 25611), Aggregatibacter actinomycetemcomitans (ATCC 33384), Fusobacterium nucleatum (ATCC 23726), and Enterococcus faecalis (ATCC 12399) containing $1.0 \times 10^{8} \mathrm{UFC} / \mathrm{mL}$, were plated in specific media. S. mutans was seeded in $\mathrm{BHI}$ agar containing $5 \%$ sucrose, $S$. aureus was seeded on Mueller-Hinton agar and left at $37^{\circ} \mathrm{C}$ in $5 \% \mathrm{CO}_{2}$ atmosphere for 48 hours. Anaerobic bacteria were plated on blood agar containing $1 \%$ menadione and $1 \%$ vitamin $\mathrm{K}$ (Difco, USA) and left at $37^{\circ} \mathrm{C}$ in an anaerobic atmosphere for 48 hours. After this, the bioactive glass test specimens, measuring $6.0 \mathrm{~mm}$ in diameter, containing propolis incorporated were planted on the surface of the agar and incubated at a temperature of $37^{\circ} \mathrm{C}$, in an environment with an atmosphere of $5 \%$ $\mathrm{CO}_{2}$ Isolated ethanol extracts of green (GPE) and red propolis (RPE), $20 \mu \mathrm{L}$ of each embedded in blanc antibiogram discs, and standardized $35 \mathrm{mg}$ tetracylin antibiogram disks (TT) (CECON- São Paulo, Brazil) were used as inhibition growth positive control for comparison with propolis incorporated into bioglass activity. Isolated Ethanol (ET) was tested also. The inhibition zones of triplicate experiments were measured after 24 and 48 hours.

\section{Statistical analysis}

GraphPad Prism version 4.0 for Windows (GraphPad Software, San Diego, CA, USA) were used for to compute the Standard deviations (SD) and data were expressed as a mean of replicates \pm SD. Significant differences between treatment groups from the antimicrobial assays were analyzed by Student's -test (significance at) using the Origin 6.0 program [47].

\section{Results and Discussion}

Table 3 shows the red propolis had higher antibacterial activity MIC and MBC $(15.3 \mu \mathrm{g} / \mathrm{mL})$ when compared with a lower MIC and MBC $(3.8 \mu \mathrm{g} / \mathrm{mL})$ of green propolis. Each of propolis studied had the same MIC and MBC value, which means that at the concentrations mentioned cell death occurs not only growth inhibition.

Tables 4 and 5 show the results of the agar diffusion test. With the ethanol exception, all products inhibited the in vitro growth of all microorganisms tested. When comparing the results observed at 24 (Table 4) and 48 (Table 5) hours, it was a small difference between the zones of inhibition were lower after 48 hours.

The green propolis showed inhibition zones smaller than the red propolis. The results observed for propolis in both the isolated extract as in association with bioglass was significantly higher compared to propolis. When compared with the positive control tetracycline, red propolis showed higher activity and significantly different. The red 
propolis was recently discovered on the coast of northeastern Brazil, the plant originated Dalbergia ecastophyllum. The chemical composition of red propolis may seem more complex than the green propolis. While green propolis is as important markers antinflammatory as artepillin $\mathrm{C}$ and flavonoids [26], red propolis have phenolics, triterepenoids, isoflavonoids, prenylated benzophenones and a naphthoquinone epoxide [43].

The propolis antimicrobial activity was also verified by others authors [48-50] who studied the antimicrobial activity of propolis extracts against $S$. mutans.

Although various factors can affect the bactericidal activity of propolis, the most important are the phytochemical constitution and form of presentation. Dalbergya ecastophylum is richer in isoflavones liquiritigenine, daidzein, isoliquiritigenine and formononetin, vestitol and neovestitol which justifies its greater antimicrobial activity [50,52-54]. The flavonoid aglycones are recognized as possible factors responsible for its antibiotic activity [26]. Whereas Baccharis dracunculifolia is richer in phenolic groups, its main chemical marker being artepillin $\mathrm{C}$, which has antioxidant and immunomodulatory activities.

When the inhibition zones of standardized disks containing the propolis extract incorporated into the bioglass were compared, there was no significant difference between them, although it was verified that the inhibition zones were smaller for the glasses into which was incorporated green propolis, and larger for those into incorporated red propolis. The extract has the same active principles as green propolis, but is form of presentation has greater diffusion capacity. With regard to the studied times, a high initial release was verified, in which a larger inhibition halo was observed in $24 \mathrm{~h}$, which was maintained for the time evaluated in this study with a variation close to $10 \%$ for all the groups,

\begin{tabular}{|l|c|c|}
\hline & $\mathrm{MIC}(\mu \mathrm{g} / \mathrm{mL})$ & $\mathrm{MBC}(\mu \mathrm{g} / \mathrm{mL})$ \\
\hline Green própolis extract & 15.3 & 15.3 \\
\hline Red própolis extract & 3.8 & 3.8 \\
\hline
\end{tabular}

Table 3: Values of minimum inhibitory concentration (MIC) and minimum bactericidal concentration (MBC) of the extracts of green and red propolis against S. aureus.

\begin{tabular}{|l|c|c|c|c|c|c|c|}
\hline & S. aureus & E. faecalis & S. mutans & $\boldsymbol{P}$. intermedia & F. nucleatum & $\boldsymbol{P}$. gingivalis & A. actinomycetem-comitans \\
\hline BGGP & $16.0 \pm 0.5$ & $13.0 \pm 0.2$ & $20.0 \pm 0.0$ & $26.0 \pm 0.2^{*}$ & $26.3 \pm 0.5^{*}$ & $17,5 \pm 0.5$ & $18.0 \pm 0.5$ \\
\hline BGRP & $22.0 \pm 0.5^{*}$ & $24.0 \pm 0.2^{*}$ & $23.0 \pm 0.5^{*}$ & $12.1 \pm 0.3$ & $15.0 \pm 0.0$ & $15.6 \pm 0.8$ & $16.8 \pm 0.2$ \\
\hline GPE & $19.0 \pm 1.0$ & $16.0 \pm 0.5$ & $22.0 \pm 0.5^{*}$ & $21.6 \pm 0.3$ & $22.0 \pm 0.0^{*}$ & $12.3 \pm 0.5$ & $18.8 \pm 0.6$ \\
\hline RPE & $22.0 \pm 0.5^{*}$ & $21.0 \pm 1.0^{*}$ & $22.0 \pm 0.5^{*}$ & $16.3 \pm 0.0$ & $18.6 \pm 0.8$ & $18.6 \pm 0.3$ & $17.5 \pm 0.25$ \\
\hline BG & $0.0 \pm 0.0$ & $0.0 \pm 0.0$ & $0.0 \pm 0.0$ & $0.0 \pm 0.0$ & $0.0 \pm 0.0$ & $0.0 \pm 0.0$ \\
\hline
\end{tabular}

Legend: * $=p<0.5$ significant

Table 4: $24 \mathrm{~h}$ susceptibility of oral pathogens bacteria to propolis samples associated with bioactive glass: green propolis (BGGP), red propolis (BGRP); propolis extracts (GPE = green propolis extract; RPE= red propolis extract), control standard tetracyclin (TT), ethanol (ET), and Bioglass (BG), with zones of inhibition in millimeter, of the agar diffusion method. Media and standard deviation $(M D \pm S D)$, mean of three experiments.

\begin{tabular}{|l|c|c|c|c|c|c|c|}
\hline & S. aureus & E. faecalis & S. mutans & P. intermedia & F. nucleatum & $P$. gingivalis & A. actinomycetem-comitans \\
\hline BGGP & $14.0 \pm 0.1$ & $11.0 \pm 0.0^{*}$ & $18.0 \pm 0.0$ & $26.0 \pm 0.0^{*}$ & $15.5 \pm 0.5$ & $17.5 \pm 0.5$ \\
\hline BGRP & $23.0 \pm 0.3^{*}$ & $21.0 \pm 0.1^{*}$ & $22.0 \pm 0.0^{*}$ & $12.1 \pm 0.3$ & $16.0 \pm 0.0$ & $15.6 \pm 0.8$ \\
\hline GPE & $19.0 \pm 1.0$ & $16.0 \pm 0.5$ & $22.0 \pm 0.5$ & $21.6 \pm 0.3$ & $22.0 \pm 0.0$ & $12.3 \pm 0.5$ \\
\hline RPE & $22.0 \pm 0.5^{*}$ & $21.0 \pm 1.0^{*}$ & $22.0 \pm 0.5^{*}$ & $16.3 \pm 0.0$ & $18.6 \pm 0.8$ & $18.6 \pm 0.3$ & $16.0 \pm 0.0$ \\
\hline BG & $0.0 \pm 0.0$ & $0.0 \pm 0.0$ & $0.0 \pm 0.0$ & $0.0 \pm 0.0$ & $0.0 \pm 0.0$ & $0.0 \pm 0.0$ & $24.8 \pm 0.3$ \\
\hline TT & $16.0 \pm 0.0^{*}$ & $19.0 \pm 0.5$ & $20.0 \pm 0.0$ & $16.5 \pm 0.5^{*}$ & $18.0 \pm 0.0$ & $18.0 \pm 0.0$ \\
\hline ET & $0.0 \pm 0.0$ & $0.0 \pm 0.0$ & $0.0 \pm 0.0$ & $0.0 \pm 0.0$ & $0.0 \pm 0.0$ & $0.0 \pm 0.0$ \\
\hline
\end{tabular}

Table 5: $48 \mathrm{~h}$ susceptibility of oral pathogens bacteria to propolis samples associated with bioactive glass: green propolis (BGGP), red propolis (BGRP); propolis extracts $(\mathrm{GPE}=$ green propolis extract; $\mathrm{RPE}=$ red propolis extract), control standard tetracyclin (TT), ethanol (ET), and Bioglass (BG), with zones of inhibition in millimeter, of the agar diffusion method. Media and standard deviation (MD \pm SD). Mean of three experiments. 
Citation: Vasconcelos WA, Braga NMA, Chitarra VR, Santos VR, Andrade ÂL (2014) Bioactive Glass-Green and Red Propolis Association: Antimicrobial Activity Against Oral Pathogen Bacteria. Nat Prod Chem Res 2: 154. doi:10.4172/2329-6836.1000154

Page 4 of 5

effective for controlling in vitro growth of the tested microorganism. Moreover, clinical phase II and phase III tests in vivo in animals and in human should be made to prove the activities observed in vitro.

\section{Acknowledgment}

The authors acknowledge the financial support of this study by Brazilian Government: Conselho Nacional de Desenvolvimento Cientifico e Tecnologico (CNPq); Fundacao de Amparo a Pesquisa do Estado de Minas Gerais (FAPEMIG), and Coordenacao de Aperfeicoamento de Pessoal de Nivel Superior (CAPES) Special thanks for Ms Silvana Maria de Souza for their help in microbiology laboratory.

\section{References}

1. Ramalingam K, Amaechi BT, Ralph RH, Lee VA (2012) Antimicrobial activity of nanoemulsion on cariogenic planktonic and biofilm organisms. Arch Oral Biol 57: $15-22$

2. Fukushima T, Iwao H, Nakazima A, Miki M, Sakai T, et al. (2009) MRSApyomyositis in a patient with acute myelogenous leukemia after intensive chemotherapy. Anticancer Res 29: 3361-3364.

3. Rokadiya S, Malden NJ (2008) An implant periapical lesion leading to acute osteomyelitis with isolation of Staphylococcus aureus. Br Dent J 205: 489-491.

4. Dessì A, Crisafulli M, Accossu S, Setzu V, Fanos V (2008) Osteo-articular infections in newborns: diagnosis and treatment. J Chemother 20: 542-550.

5. Santos FA, Bastos EM, Rodrigues PH, Uzeda M, Carvalho MAR, et al (2002) Susceptibility of Prevotella intermedia/Prevotella nigrescens (and Porphyromonas gingivalis) to propolis (bee glue) and other antimicrobia agents Anaerobe 8: 9-15.

6. Sreeja S, Babu PRS, Prathab AG (2012) The prevalence and the characterization of the enterococcus species from various clinical samples in a tertiary care hospital. J Clin Diagn

7. is AS, Costa GC, et al. (2012) Brazilian green propolis: anti-inflammatory property by an immunomodulatory activity. Evid Based Complement Alternat Med 2012: 157652.

8. de Oliveira PF, Leandro LF, Montanheiro G, Bastos JK, da Silva Filho AA, et al. (2012) Baccharin prevents genotoxic effects induced by methyl methanesulfonate and hydrogen peroxide in V79 cells. J Food Sci 77: T138-142.

9. Oliveira GA, Ferraz ER, Souza AO, Lourenço RA, Oliveira DP, et al. (2012) Evaluation of the mutagenic activity of chrysin, a flavonoid inhibitor of the aromatization process. J Toxicol Environ Health A 75: 1000-1011.

10. Righi AA, Alves TR, Negri G, Marques LM, Breyer H, et al. (2011) Brazilian red propolis: unreported substances, antioxidant and antimicrobial activities. J Sci Food Agric 91: 2363-2370.

11. Teixeira EW, Negri G, Meira RM, Message D, Salatino A (2005) Plant Origin of Green Propolis: Bee Behavior, Plant Anatomy and Chemistry. Evid Based Complement Alternat Med 2: 85-92.

12. de Almeida EB, Cordeiro Cardoso J, Karla de Lima A, de Oliveira NL, de PontesFilho NT, et al. (2013) The incorporation of Brazilian propolis into collagenbased dressing films improves dermal burn healing. J Ethnopharmacol 147 419-425.

13. Sharaf S, Higazy A, Hebeish A (2013) Propolis induced antibacterial activity and other technical properties of cotton textiles. Int J Biol Macromol 59: 408-416.

14. Santos VR (2012) Propolis: Alternative Medicine for the Treatment of Oral Microbial Diseases. Alternative Medicine 133-169.

15. Park YK, Alencar SM, Aguiar CL (2002) Botanical origin and chemical composition of Brazilian propolis. J Agric Food Chem 50: 2502-2506.

16. Batista LL, Campesatto EA, Assis ML, Barbosa AP, Grillo LA, et al. (2012) Comparative study of topical green and red propolis in the repair of wounds induced in rats. Rev Col Bras Cir 39: 515-520.

17. Marcucci MC (1995) Propolis: chemical composition, biological properties and therapeutic activity. Apidologie 26: 83-99.

18. Gazzani G, Daglia M, Papetti A (2012) Food components with anticaries activity. Curr Opin Biotechnol 23: 153-159.

19. Santos VR, Pimenta FJ, Aguiar MC, do Carmo MA, Naves MD, et al. (2005) Oral candidiasis treatment with Brazilian ethanol propolis extract. Phytother Res 19: 652-654.
20. Samet N, Laurent C, Susarla SM, Samet-Rubinsteen N (2007) The effect of bee propolis on recurrent aphthous stomatitis: a pilot study. Clin Oral Investig 11: 143-147

21. Ulpee DR (2001) Bioactive glass in the treatment of periodontal bone defects Dental Practice 2: 16-21.

22. Jebahi S, Oudadesse H, Jardak N, Khayat I, Keskes H, et al. (2013) Biologica therapy of strontium-substituted bioglass for soft tissue wound-healing: responses to oxidative stress in ovariectomised rats. Ann Pharm Fr 71: 234-242.

23. Vogel M, Voigt C, Gross UM, Müller-Mai CM (2001) In vivo comparison of bioactive glass particles in rabbits. Biomaterials 22: 357-362.

24. Rivadeneira J, Carina Audisio M, Boccaccini AR, Gorustovich AA (2013) In vitro antistaphylococcal effects of a novel $45 \mathrm{~S} 5$ bioglass/agar-gelatin biocomposite films. J Appl Microbiol 115: 604-612.

25. Wei QW, Dong YM, Chen XF, Li YL, Miao GH (2013) Growth ability of human dental pulp cells on three bioactive scaffolds. Beijing Da Xue Xue Bao 45: 484 488.

26. Kaczmarek M, Jurczyk MU, Rubis B, Banaszak A, Kolecka A, et al. (2014) In vitro biocompatibility of Ti-45S5 bioglass nanocomposites and their scaffolds. $J$ Biomed Mater Res A 102: 1316-1324.

27. Andrade AL, Manzi D, Domingues RZ (2006) Tetracycline and propolis incorporation and release by bioactive glassy compounds. Journal of NonCrystalline Solids 352: 3502-3507.

28. Alencar SM, Oldoni TL, Castro ML, Cabral IS, Costa-Neto CM, et al. (2007) Chemical composition and biological activity of a new type of Brazilian propolis: red propolis. J Ethnopharmacol 113: 278-283.

29. Daugsch A, Moraes CS, Fort P, Park YK (2008) Brazilian red propolis--chemica composition and botanical origin. Evid Based Complement Alternat Med 5: 435441

30. Trusheva B, Popova M, Bankova V, Simova S, Marcucci MC, et al. (2006) Bioactive constituents of brazilian red propolis. Evid Based Complement Alternat Med 3: 249-254.

31. Miorin PL, Levy Junior NC, Custodio AR (2003) Antibacterial activity of honey and propolis from Apis mellifera and Tetragonisca angustula agains Staphylococcus aureus. J Appl Microbiol 95: 913-920.

32. Ayres DC, Marcucci MC, Giorgio S (2007) Effects of Brazilian propolis on Leishmania amazonensis. Mem Inst Oswaldo Cruz 102: 215-220.

33. Berte LM (2007) Clinical and Laboratory Standards Institute. Clinical Laboratory Technical Procedure Manuals (CLSI/NCCLS)", Approved Guideline, Fifth Ed. MA, MT (ASCP), SBB, DLM; CQA (ASQ) CQMg

34. Park YK, Koo MH, Abreu JA, Ikegaki M, Cury JA, et al. (1998) Antimicrobial activity of propolis on oral microorganisms. Curr Microbiol 36: 24-28.

35. Leitão DP, Filho AA, Polizello AC, Bastos JK, Spadaro AC (2004) Comparative evaluation of in-vitro effects of Brazilian green propolis and Baccharis dracunculifolia extracts on cariogenic factors of Streptococcus mutans. Bio Pharm Bull 27: 1834-1839.

36. Ferreira SBS, Assis Dias BR, Obregón CS, Gomes CC, de Araujo Pereira RR et al. (2014) Microparticles containing propolis and metronidazole: in vitro characterization, release study and antimicrobial activity against periodontal pathogens. Pharm DevTechnol 19: 173-180.

37. Topcuoglu N, Ozan F, Ozyurt M, Kulekci G (2012) In vitro antibacterial effects of glass-ionomer cement containing ethanolic extract of propolis on Streptococcus mutans. Eur J Dent 6: 428-433.

38. Ramos DBM, Gomes FS, Napoleão TH, Paiva PMG, Silva MDC, et al. (2014) Antimicrobial Activity of Cladonia verticillaris Lichen Preparations on Bacteria and Fungi of Medical Importance Chinese Journal of Biology 2014: 1-7.

39. Bueno-Silva B, Alencar SM, Koo H, Ikegaki M, Silva GV, et al. (2013) Antiinflammatory and antimicrobial evaluation of neovestitol and vestitol isolated from Brazilian red propolis. J Agric Food Chem 61: 4546-4550.

40. Libério SA, Pereira AL, Araújo MJ, Dutra RP, Nascimento FR, et al. (2009) The potential use of propolis as a cariostatic agent and its actions on mutans group streptococci. J Ethnopharmacol 125: 1-9.

41. Dziedzic A, Kubina R, Wojtyczka RD, KabaÅ,a-Dzik A, Tanasiewicz M, et al (2013) The antibacterial effect of ethanol extract of polish propolis on mutans streptococci and lactobacilli isolated from saliva. Evid Based Complement Alternat Med 2013: 681891 
Citation: Vasconcelos WA, Braga NMA, Chitarra VR, Santos VR, Andrade ÂL (2014) Bioactive Glass-Green and Red Propolis Association: Antimicrobial Activity Against Oral Pathogen Bacteria. Nat Prod Chem Res 2: 154. doi:10.4172/2329-6836.1000154

42. Jorgensen JH, Swenson JM, Tenover FC, Barry A, Ferraro MJ, et al. (1994) Development of interpretive criteria and quality control limits for broth microdilution and disk diffusion antimicrobial susceptibility testing of Streptococcus pneumoniae. Journal of Clinical Microbiology 34: 2679-2684.

43. Gajan EB, Shirmohammadi A, Aghazadeh M, et al. (2013) Antibiotic Resistance in Enterococcus faecalis Isolated from Hospitalized Patients. J Dent Res Dent Clin Dent Prospects 7: 102-104.

44. Pondei K, Fente BG, Oladapo O (2013) Current microbial isolates from wound swabs, their culture and sensitivity pattern at the niger delta university teaching hospital, okolobiri, Nigeria. Trop Med Health 41: 49-53.

45. Song XL, Sun YY, Liu Y, Chen Q, Bi XX, et al. (2013) An in vitro evaluation of the effect of carboxymethyl chitosan and its composites against Enterococcus faecalis in the root canal. Shanghai Kou Qiang Yi Xue 22: 265-269.

46. Poptani B, Sharaff M, Archana G, Parekh V (2013) Detection of Enterococcus faecalis and Candida albicans in previously root-filled teeth in a population of
Gujarat with polymerase chain reaction. Contemp Clin Dent 4: 62-66.

47. Cao WB, Su D, Chen YM, Zheng YZ, Zhang FK, et al. (2012) Clinical features and antimicrobial resistance of Gram positive bacterial blood stream infection in patients with hematologic diseases. Zhonghua Xue Ye Xue Za Zhi 33: 566-569.

48. Olczak-Kowalczyk D, Daszkiewicz M, Krasuska-Sławińska, DembowskaBagińska B, Gozdowski D, et al. (2012) Bacteria and Candida yeasts in inflammations of the oral mucosa in children with secondary immunodeficiency J Oral Pathol Med 41: 568-576.

49. Allan I, Newman H, Wilson M (2001) Antibacterial activity of particulate bioglass against supra- and subgingival bacteria. Biomaterials 22: 1683-1687.

50. Krishnan V, Lakshmi T (2013) Bioglass: A novel biocompatible innovation. J Adv Pharm Technol Res 4: 78-83. 